\title{
The Iron Sulfides Crystal Growth from the Halide Melts
}

\author{
Alexander Zavrazhnov * ${ }^{a}$, Alexander Naumov ${ }^{a}$, Andrew Kosyakov ${ }^{a}$, Sergey Berezin ${ }^{a}$,
}

Vyacheslav Volkov $v^{b}$, Anastasya Sergeevac

\author{
${ }^{a}$ Voronezh State University, Universitetskaya sq., 1, 394006, Voronezh, Russia \\ ${ }^{b}$ Kurnakov Institute of General and Inorganic Chemistry, Leninsky pr., 31, 119991, Moscow, Russia \\ 'Institute of Volcanology and Seismology, Piypa, 9, 983006, Petropavlovsk-Kamchatski, Russia
}

Received: July 13, 2017; Revised: March 09, 2018; Accepted: March 26, 2018

\begin{abstract}
A new approach to a single crystals growth of the iron sulfide phases of definite structure and nonstoichiometry is developed and applied. This approach is based on the method of crystal growing from solution melts. This approach is based on the crystallization or recrystallization of iron sulfides from iron sulfide solutions in iron dihalide melts under fixed sulfur vapor pressure in the closed system in non-isothermal (two-temperature) conditions. It allows to regulate the composition and structure of the resulting iron sulphide. In particular, at a relatively low pressure $(<0.4 \mathrm{~atm})$, pyrrhotite with a trigonal $3 T$ structure is synthesized. At higher pressure pyrite $\beta-\mathrm{FeS}_{2}$ is grown. Reaction scheme for the formation of iron sulphides based on the reversible oxidation of sulfur by iron dihalide is proposed and substantiated. On the base of the \{pyrite + marcasite $\}$ - mixture annealing under the melts of the deepest eutectic compositions of $\mathrm{KCl}-\mathrm{FeCl}_{2}$ and $\mathrm{NaCl}-\mathrm{KCl}-\mathrm{FeCl}_{2}$ systems, the instability of the marcasite phase regarding the pyrite one (at least, for $T \geq 340^{\circ} \mathrm{C}$ ) was shown.
\end{abstract}

Keywords: iron sulfides, pyrite, pyrrhotite, iron halide, recrystallization.

\section{Introduction}

The intermediate phases of $\mathrm{Fe}-\mathrm{S}$ system are potentially promising materials in different areas of high-tech. Although the phases with stoichiometry similar to FeS composition ( $\gamma$-pyrrhotite, $\alpha$-pyrrhotite, troilite) are unattractive for Material Science, their nonstoichiometry-sensitive properties (magnetic and optical) may be used as indication markers for detection of valuable associated minerals in ores ${ }^{1,2}$.

High hopes for practical use are associated with iron disulfide $\mathrm{FeS}_{2}$ in pyrite phase, which is regarded as a promising material for solar energetics $\left(E_{g}=0.95 \mathrm{eV}\right.$, absorption in the near-IR region $)^{3-6} \cdot \mathrm{In}^{5,6}$ it is noted that the regulation of pyrite composition within the homogeneity region can open great possibilities for optimizing its properties.

The lack of knowledge about the phase diagram of the $\mathrm{Fe}-\mathrm{S}$ system is one of the reasons for poor reproducibility of the properties of pyrite-based materials. Whereas the hightemperature region $\left(T>680^{\circ} \mathrm{C}\right)$ is studied well enough ${ }^{7}$, (Fig. 1), the relatively low-temperature $\left(T<680^{\circ} \mathrm{C}\right)$ regions of the phase diagram of the $\mathrm{Fe}-\mathrm{S}$ system are debatable ${ }^{8-10}$. It is not still clear whether marcasite and $\mathrm{FeS}_{2}$ "hybrid" structures of pyrite and marcasite (pararammelsbergite type $^{11}$ ) are always metastable relative to pyrite with any values of $T, p, x$. There is another unclear question concerning the number of phases and structures that are present at relatively low temperatures near FeS compound at $0.46 \leq x_{\mathrm{s}} \leq 0.56$ (Fig. 1 and Fig.2). The reason for these problems is primarily related to the difficulty of achieving equilibrium states and the tendency of iron sulfides to retain their metastable states at relatively low temperatures. For this reason, many researchers prefer mineralogical findings of iron sulfides for which the relaxation time in nature may exceed by many orders the time of annealing in laboratory experiments $^{11,12}$. However, this approach does not guarantee obtaining reliable information on the phase diagram because the sample "annealing" pressure and temperature are not sufficiently known and the concentration of impurities in these minerals can be high.

In view of the above, the purpose of our study was to investigate phase relations in the system $\mathrm{Fe}-\mathrm{S}$ at moderate temperatures $\left(330-680^{\circ} \mathrm{C}\right)$. The priority task necessary for achieving this purpose was to find a method of controlled synthesis of iron sulfide single crystals. Our approach to dealing with this particular problem is described in detail in the current work which opens a series of papers. The structural analysis and the analysis of phase transformations in the $\mathrm{Fe}-\mathrm{S}$ system will be covered in the next study of this series. 


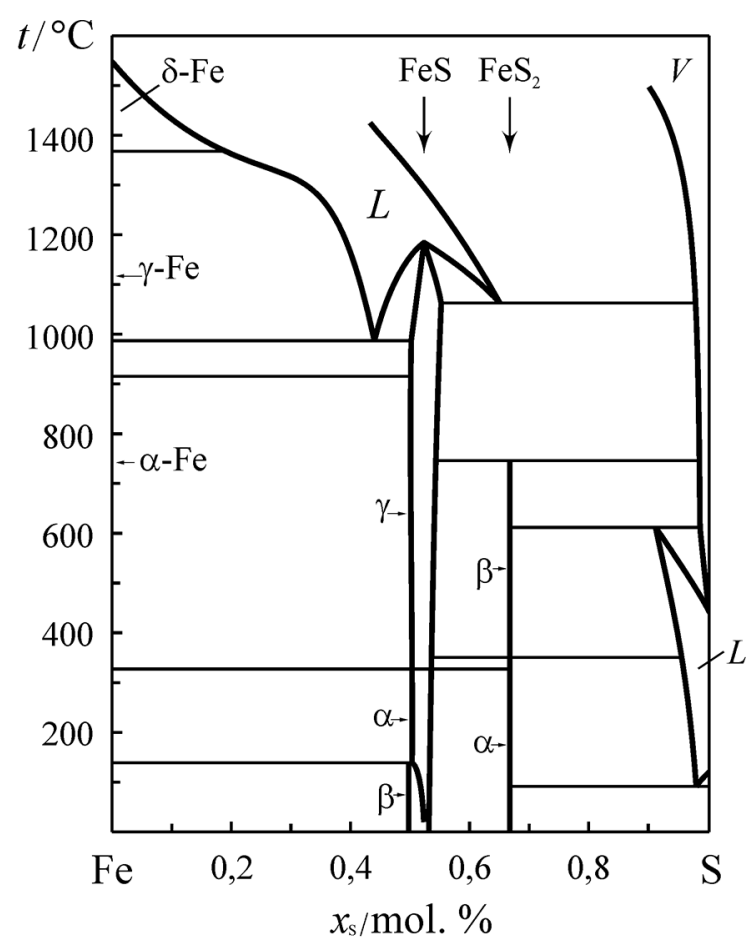

Figure 1. Phase diagram of the $\mathrm{Fe}-\mathrm{S}$ system (according to ref. $^{7}$ ).

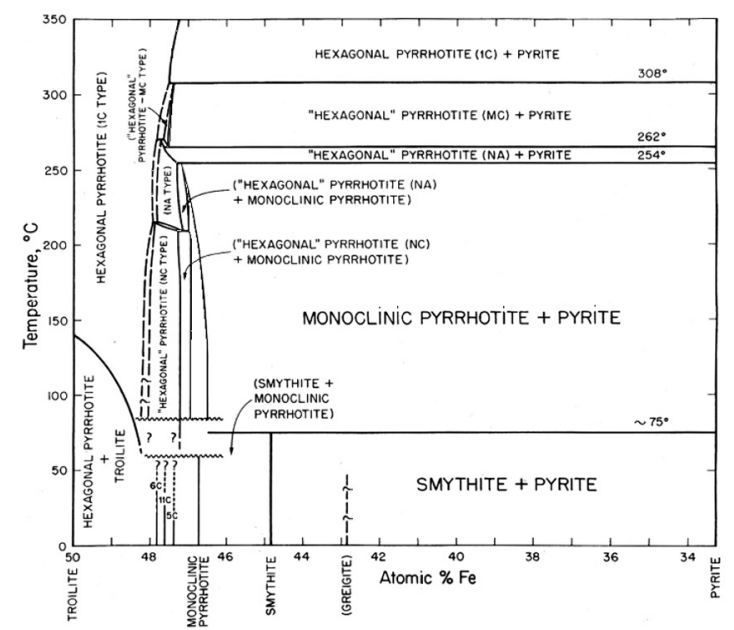

Figure 2. Low-temperature part of the $\mathrm{Fe}-\mathrm{S}$ phase diagram (according to ref. ${ }^{10}$ )

\section{Experimental}

Crystallization from iron halide melts. In order to achieve our main goal, we elaborated a new way of synthesizing iron sulfide single crystals. Our way is a variation of widely used method of crystal growing from solution-melts. It is based on recrystallization of iron sulfides from the melts of iron (II) halides $\left(\mathrm{FeX}_{2}, \mathrm{X}=\mathrm{Cl}, \mathrm{Br}, \mathrm{I}\right)$ under controlled vapor pressure of sulfur. This is an important distinctive feature of the suggested approach as it allows controlling the composition and non-stoichiometry of the resultant products.
Let us note that the method of synthesis of metal sulfides from molten salts $\left(\mathrm{FeCl}_{2}, \mathrm{FeBr}_{2}{ }^{13,14}\right.$ or $\left.\mathrm{PbCl}_{2}{ }^{15}\right)$ is described in the literature. However, the impossibility of controlling the vapor pressure of a volatile component (sulfur), when using the afore-mentioned method, led to crystallization of polycrystalline ingots that could often contain not only pyrite $\beta-\mathrm{FeS}_{2}$ but also pyrrhotite $\mathrm{Fe}_{1-x} \mathrm{~S}^{13}$. In attempts to solve the main problem of this work, the synthesis of iron sulfides from melts was performed at lower temperatures, comparing to ${ }^{13-15}$.

For crystallization from molten salts at temperatures lower than $670-680^{\circ} \mathrm{C}$ we also used the eutectic melts of $\mathrm{KCl}-\mathrm{FeCl}_{2}$ and $\mathrm{NaCl}-\mathrm{KCl}-\mathrm{FeCl}_{2}$ systems as solvents. According to our assumption, the low rate of iron sulfides crystallization allows one to approach the close-to-equilibrium state. The lower limit of the selected temperature range $\left(330^{\circ} \mathrm{C}\right)$ corresponded to the crystallization of $\mathrm{NaCl}-\mathrm{KCl}-\mathrm{FeCl}_{2}$ eutectic melt. The upper one $\left(690^{\circ} \mathrm{C}\right)$ matched the temperature of crystallization of iron sulfides from the $\mathrm{FeBr}_{2}$ melt (iron (II) bromide has the highest melting point among the halide compounds under discussion).

Crystallization or recrystallization of the iron sulfides was carried out in a two-temperature closed system according to the following scheme. The reactor for synthesis is a cylindrical silica ampoule having the internal diameter of $16-18 \mathrm{~mm}$ and the length of $300-400 \mathrm{~mm}$. The weights of pure sulfur (5$10 \mathrm{~g}$ ) and anhydrous iron (II) halide ( $4-7 \mathrm{~g}$ ) are introduced into a quartz boat. In the majority of the experiments the charge of pre-synthesized powdered mixture of $\mathrm{Fe}_{1-x} \mathrm{~S}$ and $\mathrm{FeS}_{2}(0.3-0.5 \mathrm{~g})$ is added to the boat too. Then the boat is placed at the end of the reactor. After evacuation and sealing, the reactor is placed in a horizontal two-zone furnace. When conducting an experiment, the higher temperature $T_{2}$ corresponds to the end of the ampoule with the mixture of the sulfides and the iron halide. The lower temperature $T_{1}$ corresponds to the opposite end where the liquid sulfur exists. The value of temperature $T_{1}$ determines the saturated vapor pressure of sulfur. Since all the phases of the Fe-S system are characterized by the incongruent sublimation, when only molecular species of sulfur are in equilibrium with the solid sulfides ${ }^{16}$, the total pressure $p_{\mathrm{S}}$ should determine both the structure and the nonstoichiometry of the grown iron sulfide crystals. The vapor pressure of sulfur was set in the range from 0.25 to $9.5 \operatorname{bar}\left(360 \leq T_{1} \leq 640^{\circ} \mathrm{C}\right)$.

We used three experimental modes. In the first one the charge of $\left\{\mathrm{Fe}_{1-x} \mathrm{~S}+\mathrm{FeS}_{2}\right\}$-mixture is not introduced into the system at all. In this case the crystallization of iron sulfides from the iron halide melts is related to the redox reaction (see below).

In the second and third modes the charge of initial $\left\{\mathrm{Fe}_{1-x} \mathrm{~S}+\mathrm{FeS}_{2}\right\}$-mixture is used. In the second mode the temperatures $T_{2}$ and $T_{1}$ remained steady from the beginning until the end of the experiment. The boat with the substances 
was held for 20 hours at a temperature $\sim 15^{\circ} \mathrm{C}$ higher than the melting point of the iron (II) halide $\left(T_{2}=685-700^{\circ} \mathrm{C}\right)$ to saturate that melt with the iron sulfide. Upon the completion of this heat treatment a number of fine $\mathrm{FeS}_{y}$ single crystals were obtained. In this case the crystal growth takes place at the expense of isothermal recrystallization: the mass transfer from the small crystals to the larger ones via the liquid phase.

In the experiments of the third type the saturation of the melt with iron sulfides and their subsequent crystallization was regulated by varying the temperature $T_{2}$. As in the previous (second) mode, the boat with the substances was held for 20 hours at a temperature of $685-700^{\circ} \mathrm{C}$. Then gradually, within a few hours, the temperature $T_{2}$ was reduced to the value $10-15^{\circ} \mathrm{C}$ below the melting point of iron (II) halide $\left(T_{m}=670-685^{\circ} \mathrm{C}\right)$. The temperature $T_{1}$ and, consequently, the pressure of sulfur vapor remained fixed. After the complete crystallization the system was cooled in the off mode furnace. The cooling rate of the hot zone was about $10 \mathrm{~K} / \mathrm{min}$.

To isolate the crystallized iron sulfides from halogenides, the resulting heterogeneous mixture was treated with distilled water for leaching the highly soluble halides. The precipitate was successively washed by ethanol and toluene and then dried. During multiple repeated washes, a highly dispersed powder of the initial iron sulfides was almost completely separated from the well grown material.

Annealing experiments. To clarify the stability of marcasite relative to pyrite, a powder samples of pyrite and marcasite mixture were annealed in contact with eutectic $\mathrm{KCl}-\mathrm{FeCl}_{2}\left(38 \mathrm{~mol} . \% \mathrm{FeCl}_{2}, t_{\text {eut }} \approx 350{ }^{\circ} \mathrm{C},{ }^{17}\right)$ or $\mathrm{NaCl}-\mathrm{KCl}-\mathrm{FeCl}_{2}\left(12 \mathrm{~mol} . \% \mathrm{NaCl}, 48 \mathrm{~mol} \% \mathrm{FeCl}_{2}\right.$, $\left.t_{\text {eut }}=305 \pm 2{ }^{\circ} \mathrm{C}^{18}\right)$ melts. Since the reproducible synthesis of marcasite $\left(\alpha-\mathrm{FeS}_{2}\right)$ is complicated, in our experiments a natural mixture of pyrite and marcasite of the Nizhne-Koshelev hydrothermal deposit (Kamchatka Peninsula) was taken as the starting sample. The chloride mixture amount was such that under the experimental conditions the melt completely covered the $\mathrm{FeS}_{2}$ powder, which was well wetted by the molten chlorides. After evacuation and sealing, the ampoule with substances was placed in an isothermal section of the furnace at a temperature of $340^{\circ} \mathrm{C}$. Then the annealing was carried out. It was completed by cooling in the off mode furnace. The iron sulfides were separated from the chlorides according to the procedure described above.

$\mathrm{X}$-ray phase analysis and electron microscopy. The samples were identified by the X-ray powder diffraction (XRD). The powder patterns were recorded on a Shimadzu XRD-7000 powder diffractometer using monochromatized $\mathrm{Cu} K_{\alpha 1}$-radiation. The data were obtained with a sampling rate of $0.05^{\circ}(2 \Theta$ scale $)$ with an exposure time of $6.0 \mathrm{~s}$ at the point. Model powder patterns for known structures were calculated according to the published data (PowderCell 2.4 program).

The obtained samples were also investigated by scanning electron microscopy (SEM) using a JEOL JSM-7001F device. For a number of single crystals, a quantitative analysis was carried out with the use of an S8-Tiger X-ray fluorescence analyzer.

\section{Results and Discussion}

Phase composition and phase transformations. As it was shown by the $\mathrm{X}$-ray studies, the crystals grown from $\mathrm{FeCl}_{2}$ and $\mathrm{FeBr}_{2}$ melts at a vapor pressure of sulfur above 0.42 bar represent the only the phase of pyrite $\beta-\mathrm{FeS}_{2}$ (Fig. 3). These crystals are characterized mainly by the combined habit of the cube and pentagonal dodecahedron (Fig. 4a). The growth steps are visible on some faces (Fig. 4b). The smoothest faces are formed at the sulfur vapor pressures up to 2 bar, and at the higher pressures the characteristic growth patterns appear on some faces apparently related to the emergence of dislocations (Fig. 4c). The experimental lower limit value of the sulfur vapor pressure ( 0.42 bar), above which the only phase of pyrite crystallizes at a temperature of $680^{\circ} \mathrm{C}$, correlates with the data of ${ }^{6,19}$ concerning the $P-T$ dependency for the $\gamma-\mathrm{Fe}_{1-x} \mathrm{~S}-\beta-\mathrm{FeS}_{2}-V$ equilibrium: 0.39 bar for temperature of $680^{\circ} \mathrm{C}$. (That value was calculated using the equation from the work $^{6}: \ln [P /$ torr $]=-40317 /[T / \mathrm{K}]+48.000$; the data of ${ }^{19}$ give practically the same result).

The lattice constant for the cubic pyrite structure (S.G. $P a \overline{3}$ ) exhibits weak sensitivity to the sulfur vapor pressure during the synthesis. The maximum value of the lattice constant is $0.54130 \pm 0.00010 \mathrm{~nm}$ and the minimum one is $0.54116 \pm 0.00001 \mathrm{~nm}$. So, the pyrite lattice constants are somewhat smaller than it is usually published (for example, $\left.0.547 \mathrm{~nm}^{11}\right)$.

The annealing of the pyrite-marcasite mixture with the eutectic $\mathrm{KCl}-\mathrm{FeCl}_{2}$ melt was carried out at 365, 400, 450 and $500^{\circ} \mathrm{C}$ for 36 hours. The annealing at the highest temperature $\left(500^{\circ} \mathrm{C}\right)$ led to the complete transformation of marcasite into pyrite, the annealing at the lowest temperature $\left(365^{\circ} \mathrm{C}\right)$ left the sample practically unchanged. At two intermediate temperature values, an apparent decrease of marcasite phase content in the sample was observed (Figs. 5 and 6). The calculated marcasite volume fractions in the annealed samples are given in Table 1 .

To examine the $\alpha-\mathrm{FeS}_{2} \rightarrow \beta-\mathrm{FeS}_{2}$ transformation at low temperatures, an identical experiment was carried out at $340^{\circ} \mathrm{C}$ using a more fusible eutectic $\mathrm{NaCl}-\mathrm{KCl}-\mathrm{FeCl}_{2}$ and a much longer annealing time $(160 \mathrm{~h})$. This experiment, according to X-ray data, led to the complete transformation of marcasite into pyrite (Fig. 5). Thus, metastability of marcasite relative to pyrite is decisively proven (at least for $T \geq 340^{\circ} \mathrm{C}$ ). 


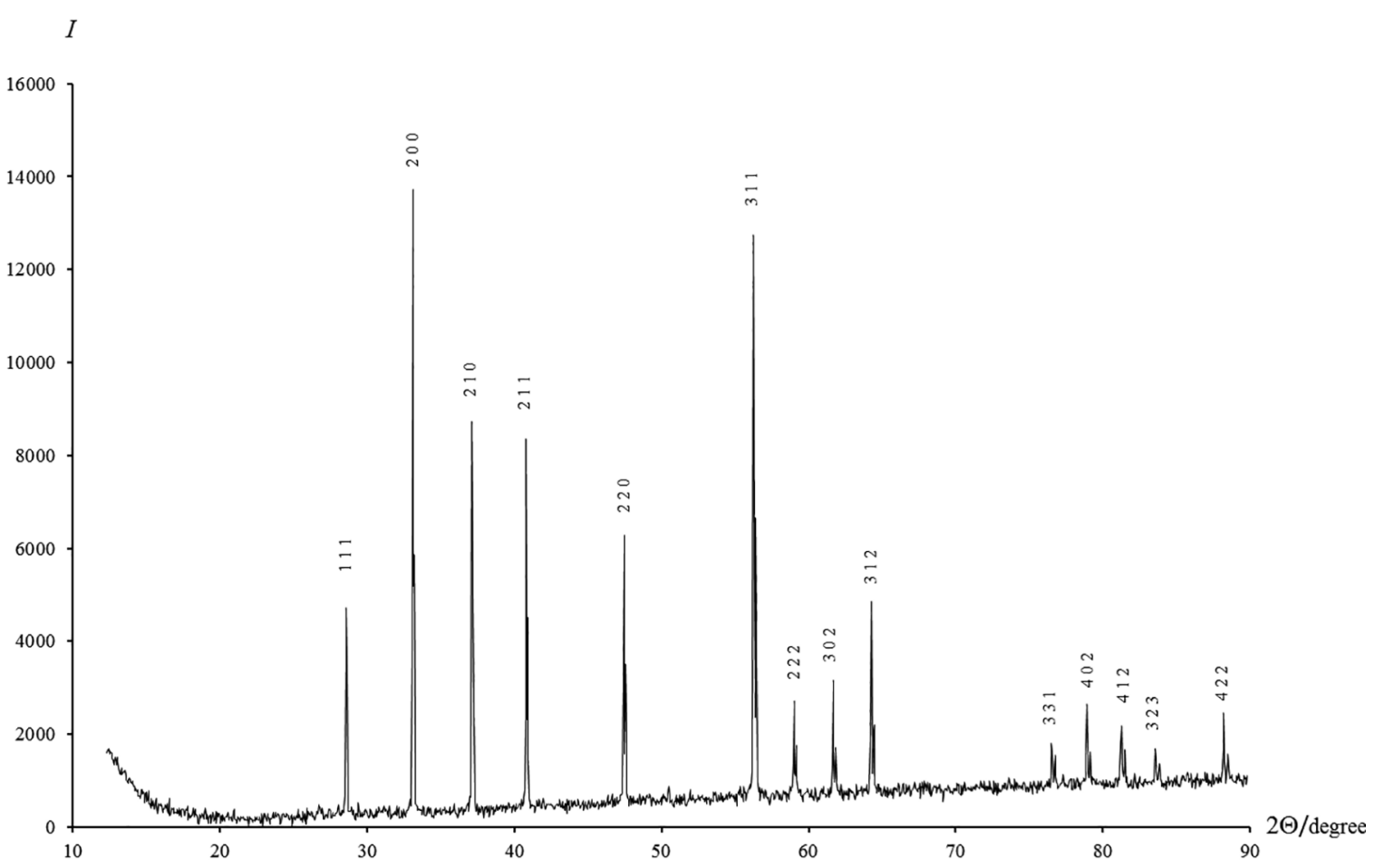

Figure 3. Powder pattern of the $\mathrm{FeS}_{2}$ samples grown at sulfur vapor pressure of 4 bar.

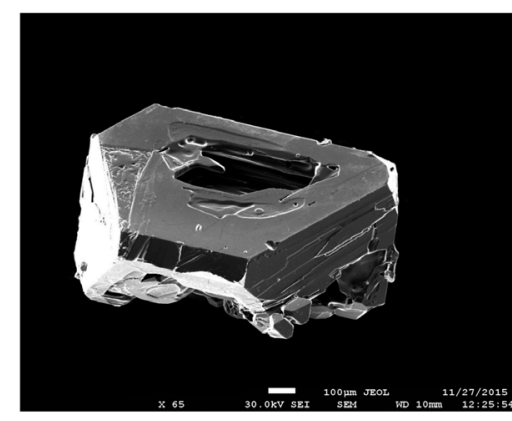

(a)

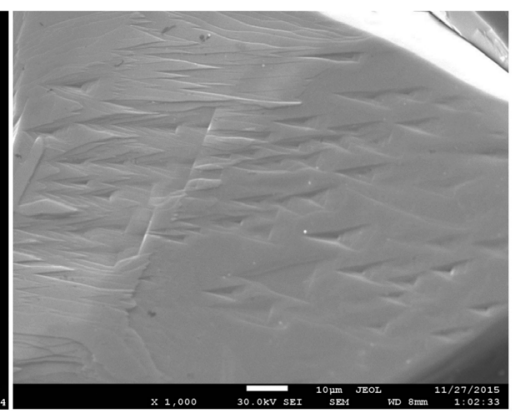

(b)

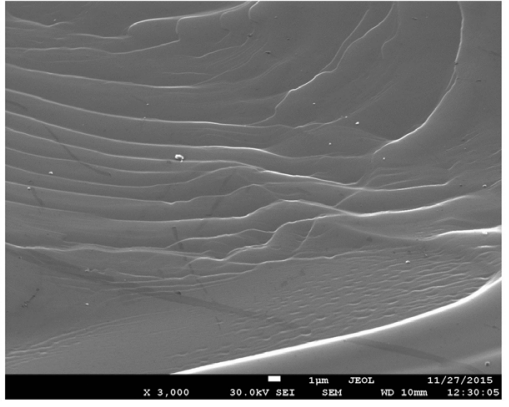

(c)

Figure 4. Surface images for the pyrite single crystals, grown by the iron sulfide recrystallization from $\mathrm{FeBr}_{2}$ melts in a contact with sulfur vapor: $P_{\text {tot. }\left(\mathrm{S}_{x}\right)}=1$ bar, $(\mathrm{a}, \mathrm{b})$ and $P_{\left.\text {tot.(S } \mathrm{S}_{x}\right)}=10 \mathrm{bar}(\mathrm{c})$.

In our opinion, the most interesting data were obtained for the samples grown from melts at low sulfur vapor pressures: 0.20 bar or less. In this case the phase of the stoichiometry similar to FeS (with an admixture of pyrite phase) was crystallized from the iron (II) halide melts. The XRD results showed that it is a trigonal phase (S.G. P3 21) having the defect structure based on $\gamma-\mathrm{Fe}_{1-x} \mathrm{~S}$ (S.G. $P 6_{3} / m m c$, structural type NiAs). This phase was characterized as a type of pyrrhotite- $3 T^{20}$ having the lattice constants: $a \in[0.68718$; $0.68836] \mathrm{nm}$ and $c \in[1.70692 ; 1.71082] \mathrm{nm}$.

As the vapor pressure of sulfur increases, the lattice parameter of the trigonal pyrrhotite decreases. These results are correlated well with the well-known fact that the predominant defects in pyrrhotites are the vacancies in the iron sublattice: an increase in the concentration of these vacancies with an increase in the vapor pressure of sulfur should lead to a decrease in the values of $a$ and $c$.

The reaction scheme of iron sulfides crystallization for the description of the equilibrium states and the heterophase equilibrium displacement. Taking into account a very noticeable spontaneous electrolytic ionization of the iron halogenides-based melts ${ }^{21,22}$, we propose the following hypothesis. We assume that the basis for the formation of iron sulfides from halide melts under the described conditions is the reversible oxidation of liquid iron (II) halides reaction by the free sulfur to free halogens: 


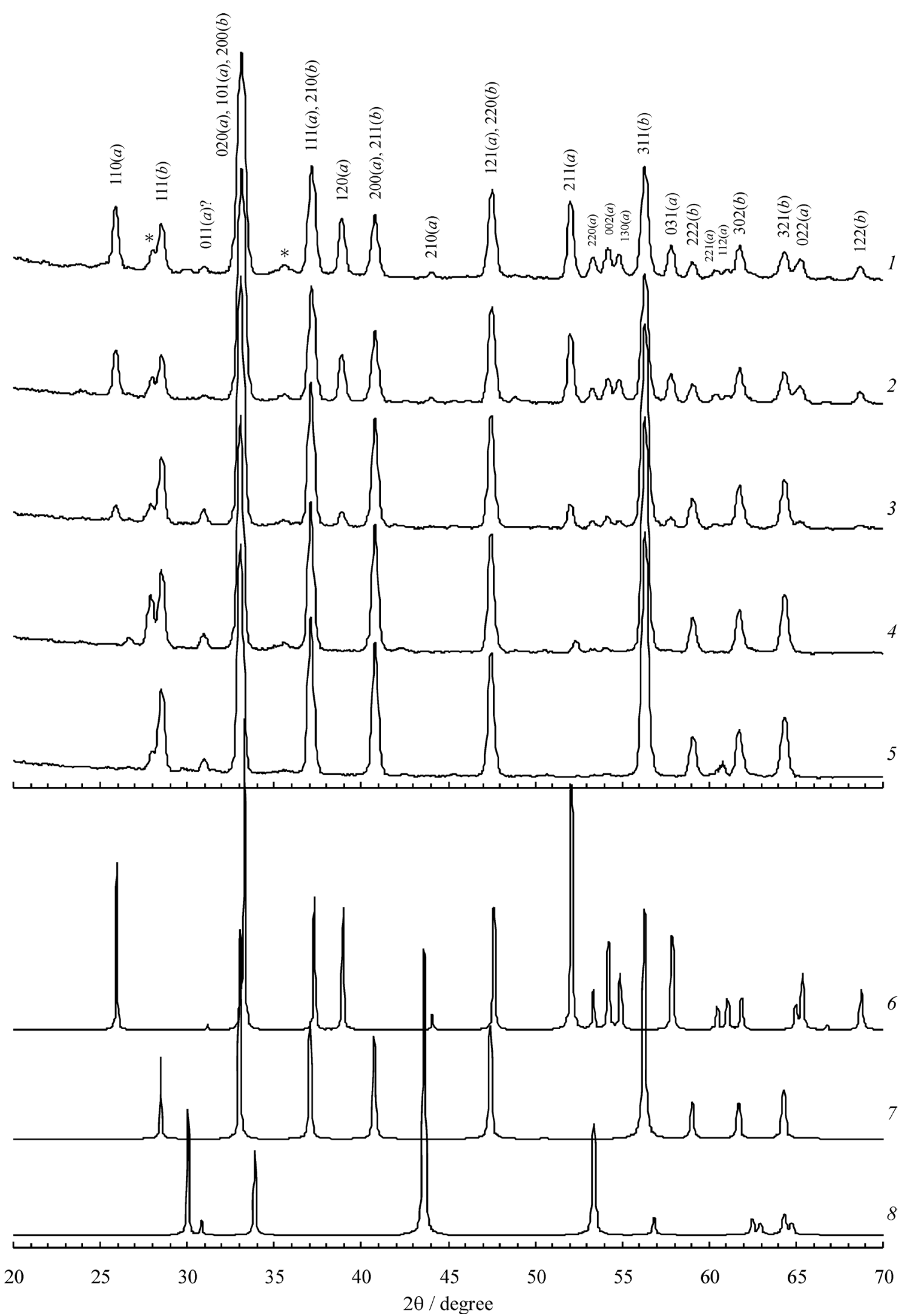

Figure 5. Diffraction powder patterns $\left(\mathrm{Cu}-\mathrm{K}_{\alpha 1}\right.$ radiation) of pyrite-marcasite mixtures ( 1 - initial native sample), which had 36-hours annealing under the $\mathrm{KCl}-\mathrm{FeCl}_{2}$ eutectic melts at the following temperatures: $2-365 ; 3-400 ; 4-450 ; 5-500{ }^{\circ} \mathrm{C} ; a-$ marcasite $\alpha-\mathrm{FeS}_{2}$, Pnnm) peaks; $b$ - pyrite $\left(\beta-\mathrm{FeS}_{2}, P a \overline{3}\right)$ peaks; ${ }^{*}$ - the notation for the silicates impurities. 6 - 8 - calculated powder pattern: 6 - marcasite $\alpha-\mathrm{FeS}_{2}, 7$ - pyrite $\beta-\mathrm{FeS}_{2}, 8$ - pyrrhotite $\gamma-\mathrm{Fe}_{1-x} \mathrm{~S}$. 


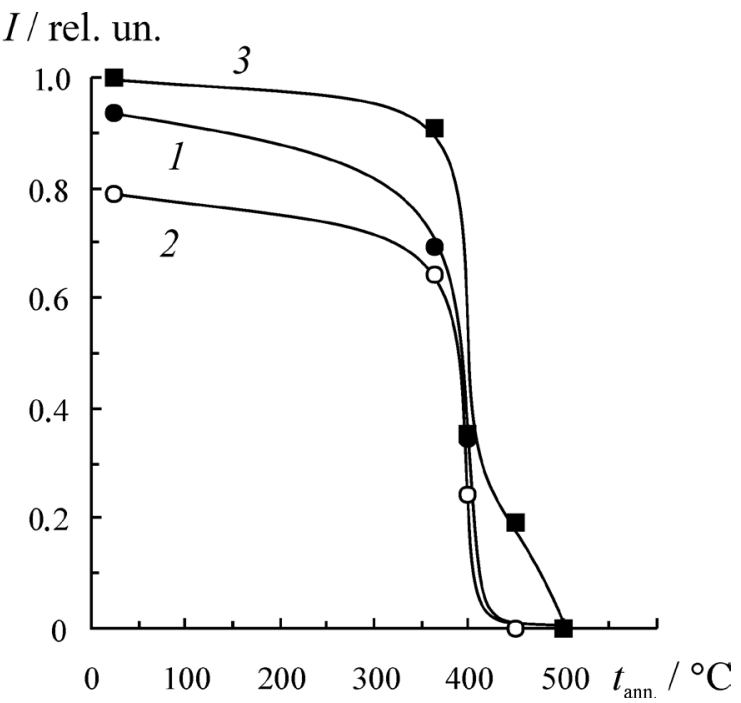

Figure 6. The change in the relative intensity of the marcasite reflexes after the 36-hours annealing of pyrite-marcasite mixtures: $1-100 ; 2-120 ; 3$ - to 211 .

Table 1. Pyrite-phase volume fractions in the pyrite-marcasite mixtures after the $36 \mathrm{~h}$-annealing of the native pyrite-marcasite samples under the $\mathrm{KCl}-\mathrm{FeCl}_{2}$ eutectic melt

\begin{tabular}{cc}
\hline $\boldsymbol{t}_{\text {annealing }}{ }^{\circ} \mathrm{C}$ & Pyrite volume fraction, $\%$ \\
\hline Init. Sample & 47.2 \\
365 & 46.8 \\
400 & 68.6 \\
450 & 80.7 \\
500 & 100.0 \\
\hline
\end{tabular}

$$
\frac{n}{2} \mathrm{~S}_{2}^{(V)}+2 \mathrm{X}^{-(L)}=\mathrm{S}_{n}^{2-(L)}+\mathrm{X}_{2}^{(V)} \quad(\mathrm{X}=\mathrm{C} 1, \mathrm{Br}, \mathrm{I})
$$

where $V$ is the vapor phase; $L$ is the melt; $n=1$ or 2 . The reduced species of sulfur (ions $\mathrm{S}_{2}{ }^{2-}$ or $\mathrm{S}^{2-}$ ), released in (1) are bounded by the iron ions $\left(\mathrm{Fe}^{2+}\right)$ to the solid iron sulfide:

$$
\mathrm{S}_{n}^{2-(L)}+\mathrm{Fe}^{2+(L)}=\mathrm{Fe}_{\mathrm{Fe}}+\left(\mathrm{S}_{n}\right)_{\mathrm{S}}
$$

where the symbols $\mathrm{Fe}_{\mathrm{Fe}}$ and $\left(\mathrm{S}_{n}\right)_{\mathrm{S}}$ stand for iron and sulfur in the sublattices of these components in the crystals of pyrrhotite or pyrite. In addition to those above, the quasi-chemical reactions cause the specific defect formation in iron sulfides.

The equilibria (1) and (2) displacement with varying pressure and temperature can lead to the crystallization of iron sulfides or, conversely, to their dissolution in the $\mathrm{FeX}_{2}$ melts. Moreover, varying the sulfur pressure, we can change the sulfur content in solid sulfides, i.e. - vary the phase composition and nonstoichiometry of these solids. Thus, let us introduce the $K_{P}^{\#}$-value ${ }^{23}$ for equation (1):

$$
K_{P}^{\#}=\frac{p_{\mathrm{x} 2}}{p_{\mathrm{S}_{2}}} ; \mathrm{X}=\mathrm{C} 1, \mathrm{Br}, \mathrm{I}
$$

The value of $K_{P}^{\#}$ relates the values of the partial pressures of sulfur and liberated halogen $\left(\mathrm{X}_{2}\right)$ vapors in the equation (1) and allows one to determine the value of the chemical potential of sulfur $\left(\mu_{\mathrm{S}_{n}}\right)$ in the solid sulfide to within a term depending on the temperature $(T)$, pressure $(P)$ and composition of the liquid phase $\left(x^{(L)}\right)$

$$
\mu_{S_{n}}^{(S)}=R T \ln K_{P}^{\#}+f\left(T, P, x^{(L)}\right)^{23}
$$

According to (4) it is easy to see that an increase in the sulfur pressure results in a decrease of the chemical potential of sulfur in the sulfide $\left(\mu_{\mathrm{S}_{n}}\right)$ and in an increase of the sulfur content $\left(x_{\mathrm{s}}\right)$ in it.

Combining the equations (1) and (2) with the assumption of the strict stoichiometry for the pyrrhotite and pyrite phases and simplifying the subscription $\left\{\mathrm{Fe}_{\mathrm{Fe}}+\left(\mathrm{S}_{n}\right)_{\mathrm{S}}\right\}$ to $\mathrm{FeS}$ and $\mathrm{FeS}_{2}$ formulas, one can obtain equations (5) for $n=2$ and (6) for $n=1$.

$$
\mathrm{FeX}_{2}^{(L)}+\mathrm{S}_{2}^{(V)}=\mathrm{FeS}_{2}^{(S)}+\mathrm{X}_{2}^{(V)} \quad(\mathrm{X}=\mathrm{C} 1, \mathrm{Br}, \mathrm{I})
$$

$$
\mathrm{FeX}_{2}^{(L)}+\frac{1}{2} \mathrm{~S}_{2}^{(V)}=\mathrm{FeS}^{(S)}+\mathrm{X}_{2}^{(V)} \quad(\mathrm{X}=\mathrm{C} 1, \mathrm{Br}, \mathrm{I})
$$

Estimated thermodynamic calculations performed using the data of ${ }^{24}$ show that for the reactions the enthalpy value $\left(\Delta H^{\circ}\right.$ ) for the equations (5) and (6) must be positive. This means that a decrease in the temperature $T_{2}$ should lead to a displacement of the equilibria (5) and (6) to the right and to the crystallization of the iron sulfide of a certain stoichiometry. It is also obvious that an increase in the sulfur vapor pressure should lead to a similar result. The structure of the obtained solid, as well as its composition, should depend both on the temperature of the melt $\left(T_{2}\right)$ and on the sulfur vapor pressure that is set by the cold zone temperature $\left(T_{1}\right)$.

The hypothesis of a significant contribution of the equilibrium (1) to the formation of iron sulfides from iron (II) halides required verification, since it is difficult imagine elemental sulfur oxidizing chlorides and bromides to elemental halogens at any their appreciable concentrations. During such verification, the proposed crystallization mechanism was confirmed by the following experimental results:

1. Pyrite precipitation from the liquid iron (II) bromide during the reaction with the sulfur vapor (see above, the first mode of the crystallization procedure). In case of $\mathrm{FeBr}_{2}$ and $\mathrm{FeI}_{2}$ melts the iron sulfides crystal growing can even be achieved without addition of initial $\mathrm{FeS}_{n}$-charge. Thus, the crystallization of a pure pyrite phase $\beta-\mathrm{FeS}_{2}$ was observed under the conditions when the sulfur vapor pressure in an ampoule was set constant (4 atm, which corresponds to 
$T_{1}=450^{\circ} \mathrm{C}$ ), and the $\mathrm{FeBr}_{2}$ melt was kept for several hours at $680^{\circ} \mathrm{C}$. The data from this experiment - the known volume of the ampoule $(180 \mathrm{ml})$ and the mass of the precipitated pyrite $(0.3001 \mathrm{~g})-$ make it possible to roughly estimate the $K_{P}^{\#}$ value at an average temperature of the hot zone of $680^{\circ} \mathrm{C}$ (for $K_{P}^{\#}$ see the equations 3 and 4). To approximate $K_{P}^{\#}$ for $\mathrm{X}=\mathrm{Br}$, the required partial vapor pressure of bromine vapor was determined from the ideal gas equation, taking into account the identity $n_{\mathrm{Br}_{2}}{ }^{(l)}=n_{\mathrm{Fes}_{2}}$ and the average temperature between $T_{2}$ and $T_{1}$. The resulting value of $K_{P}^{\#} \approx 5.10^{-3}$ appears to be somewhat overestimated, since calculations did not take into account the possible solubility of bromine in the hot melt of sulfur, as well as the partial binding of bromine to iron tribromide.

2. Practically irreversible iron sulfides crystallization during the interaction of sulfur vapors with iron (II) iodide melts. During the interaction of the $\mathrm{Fe}_{2}$ melt with sulfur vapors, iodine vapor was always released. This was determined by the characteristic vapor colour easily distinguishable even against the background of coloured sulfur vapor.

The blackening of the initially red-brown sulfur melt was also observed for the reason of the high solubility of molecular iodine in liquid sulfur. At the same time, the iron sulfides crystallized: at $T_{1} \leq 400{ }^{\circ} \mathrm{C}$ it was a pure pyrite phase, and at $T_{1} \leq 300{ }^{\circ} \mathrm{C}$ it was a mixture of pyrite and trigonal pyrrhotite $3 T-\mathrm{Fe}_{1-x} \mathrm{~S}$. Such crystallization took place even under constant temperature conditions and resulted in complete conversion of the $\mathrm{FeI}_{2}$ melt into the $3 T-\mathrm{Fe}_{1-x} \mathrm{~S}+\mathrm{FeS}_{2}$ or $\beta-\mathrm{FeS}_{2}$ (pyrite) phases.

However, at this stage the practical use of the $\mathrm{FeI}_{2}$-melts for the crystal growth of iron sulfides of certain composition seems to be doubtful because liberated iodine has a high solubility in liquid sulfur. Indeed, to maintain the vapor pressure of sulfur $\left(P_{\text {tot. } \mathrm{S}_{\mathrm{Y}}}\right)$ constant, one should change the temperature $T_{1}$ over the course of experiment, because if the iodine is present in liquid sulfur, then the sulfur vapor pressure value becomes a function of both the temperature and the concentration: $P_{\text {tot. } \mathrm{S}_{\mathrm{x}}}=f\left(T_{1}, x_{\mathrm{I}_{2}}\right)$. Moreover, the iodine concentration in the liquid sulfur $\left(x_{\mathrm{I}^{2}}\right)$ should be changed with iodine liberation in the gas phase.

3. Oxidizing properties of sulfur condensate that was obtained after recrystallization experiments from the bromide and chloride melts. After the experiments on the recrystallization of iron sulfides from the $\mathrm{FeBr}_{2}$ and $\mathrm{FeCl}_{2}$ melts, the excess sulfur was condensed in the free end of the reactor. The removed sulfur was powdered and treated with a concentrated aqueous solution of freshly prepared ferric chloride (II). Then the Fe(III) appearance was observed in the solution (for example with a thiocyanate test). It should be noted that the pure powdered sulfur does not react with the iron (II) salts solutions.
Iron trichlorides and tribromides could be formed according to the reaction (6). Free halogen $\left(\mathrm{Cl}_{2}, \mathrm{Br}_{2}\right)$ liberated in Eq. (1), can be partially bonded to volatile iron trihalide:

$$
\mathrm{FeX}_{2}^{(L)}+\frac{1}{2} \mathrm{X}_{2}^{(V)}=\mathrm{FeX}_{3}^{(V)} \quad(\mathrm{X}=\mathrm{C} 1, \mathrm{Br})
$$

These volatile species can be condensed in the cold zone and then $\mathrm{Fe}$ (III) compounds can be found in aqueous solutions as after the water treatment.

We would like to point out that the proposed scheme (equations 1 and 2) is aimed at the thermodynamic description of the system. First of all, this scheme is intended to show the possibility of growing the crystals of the very sulfide $\left(\mathrm{Fe}_{1-x} \mathrm{~S}\right.$ or $\left.\mathrm{FeS}_{2}\right)$ when we change the pressure of sulfur even if the initial charge of $\left\{\mathrm{Fe}_{1-x} \mathrm{~S}\right.$ or $\left.\mathrm{FeS}_{2}\right\}$ is absent. At this point we cannot assert that the role of these equations is kinetically significant.

\section{Conclusions}

Thus, we can consider proven the assumption about an essential contribution of equilibria (1) and (2) to the formation of iron sulfides according to the procedure described in this paper. It should be noted that the possibility of oxidizing halides $\left(\mathrm{Cl}^{-1} ; \mathrm{Br}^{-1}\right)$ with sulfur $\left(\mathrm{S}^{0}\right)$ was proved both experimentally ${ }^{25,26}$ and in thermodynamic calculations ${ }^{26}$.

The direction of the iron mass transfer - the iron insertion into the growing sulphide phase or its extraction by the halide melt - is determined by the thermodynamic parameters of the experiment (temperature, sulfur vapor pressure, the composition of the melt). This fact suggests that the equilibria considered here are close to selective chemical vapor transport (SCVT). We described SCVT reactions in works ${ }^{27-29}$. A distinctive feature of the transport transformations considered in this paper is that these transformations occur with the participation of the liquid phase (molten salts). The low diffusion rates in the liquid (compared to the velocities in the vapor) lead to low rates of formation of the solid phases. In some cases this provides a clear advantage since it makes it possible to perform the crystal growth in a quasistatic regime, obtaining practically equilibrium states. Last but not least, in case of $\mathrm{FeBr}_{2}$ and $\mathrm{FeI}_{2}$ melts the iron sulfides crystal growing can even be achieved without addition of initial $\left\{\mathrm{Fe}_{1-x} \mathrm{~S}+\mathrm{FeS}_{2}\right\}$-charge.

Let us go back to the experimental proof of the metastability of marcasite with respect to pyrite. In our opinion, the role of the molten iron halides in this annealing experiment is to reduce the kinetic difficulties in the iron transfer between the competing phases of pyrite and marcasite. (Difficulties in the sulfur transfer should be affected much less because of the appreciable saturated sulfur vapor pressure over iron disulphide). As a result, crystals of a more stable phase are allowed to grow by dissolving a less stable phase. Without 
the presence of a transporting agent, the component transport from one phase to another must have very low speeds; then a phase transformation cannot be observed.

\section{Summary}

I A procedure of synthesis of the iron sulphide singlecrystals having a given structure and composition is developed and applied. The technique is based on interaction of iron halide melts with sulfur vapors in a closed non-isothermal system at varying pressures of these vapors and allows to regulate the composition and structure of the resulting iron sulphide. In particular, at a relatively low pressure $(<0.4 \mathrm{~atm})$, pyrrhotite with a trigonal $3 T$ structure is synthesized. At higher pressure pyrite $\beta-\mathrm{FeS}_{2}$ is grown.

II Reaction routes for the formation of iron sulphides based on the reversible oxidation of sulfur by iron dihalide are proposed and substantiated.

III On the base of the \{pyrite + marcasite - mixture annealing under the melts of the deepest eutectic compositions of $\mathrm{KCl}-\mathrm{FeCl}_{2}$ and $\mathrm{NaCl}-\mathrm{KCl}-\mathrm{FeCl}_{2}$ systems, the instability of the marcasite phase regarding the pyrite one (at least, for $T \geq 340^{\circ} \mathrm{C}$ ) was shown.

\section{Acknowledgements}

The authors are grateful for the helpful comments which were received from Dr. James McKee and Ms. Marina Berezina, Max-Planck-Institute for Radio Astronomy, Bonn, Germany.

\section{References}

1. Rundquist DV, Gillen C, eds. Ore Deposits of the East European \& Siberian Cratons. Volume 30. Amsterdam: Elsevier; 1997. $457 \mathrm{p}$.

2. Wozniakiewicz PJ, Ishii HA, Kearsley AT, Burchell MJ, Bland PA, Bradley JP, et al. Investigation of iron sulfide impact crater residues: A combined analysis by scanning and transmission electron microscopy. Meteoritics \& Planetary Science. 2011;46(7):1007-1024. DOI: 10.1111/j.1945-5100.2011.01206.x

3. Meng L, Liu YH, Tian L. Structural, optical and electrical properties of polycrystalline pyrite $\left(\mathrm{FeS}_{2}\right)$ films obtained by thermal sulfuration of iron films. Journal of Crystal Growth. 2003;253(1-4):530-538. DOI: 10.1016/S0022-0248(03)01040-6

4. Milichko VA, Shalin AS, Mukhin IS, Kovrov A, Krasilin A, Vinogradov A, et al. Solar photovoltaics: Current state and trends. Uspekhi Physicheskikh Nauk. 2016;186(8):801-852. DOI: 10.3367/UFNr.2016.02.037703

5. Ellmer K, Höpfner C. On the stoichiometry of the semiconductor pyrite $\left(\mathrm{FeS}_{2}\right)$. Philosophical Magazine A. 1997; 75(4):1129-1151. DOI: $10.1080 / 01418619708214015$
6. Ennaoui A, Fiechter S, Pettenkofer C, Alonso Vante N, Büker $\mathrm{K}$, Bronold $\mathrm{M}$, et al. Iron disulfide for solar energy conversion. Solar Energy Materials and Solar Cells. 1993;29(4):289-370. DOI: 10.1016/0927-0248(93)90095-K

7. Bannykh OA, Budberg PB, Alisova SP. Diagrammy sostoyaniya dvoynykh i mnogokomponentnykh sistem na osnove zheleza. Moscow: Metallurgiya; 1986, 440 p. (in Russian)

8. Kruse O. Mössbauer and X-ray study of the effects of vacancy concentration in synthetic hexagonal pyrrhotites. American Mineralogist. 1990;75:755-763.

9. Grønvold F, Stølen S. Thermodynamics of iron sulfides II. Heat capacity and thermodynamic properties of $\mathrm{FeS}$ and of $\mathrm{Fe}_{0875} \mathrm{~S}$ at temperatures from $298.15 \mathrm{~K}$ to $1000 \mathrm{~K}$, of $\mathrm{Fe}_{0.98} \mathrm{~S}$ from $298.15 \mathrm{~K}$ to $800 \mathrm{~K}$, and of $\mathrm{Fe}_{0.89} \mathrm{~S}$ from $298.15 \mathrm{~K}$ to about 650 $\mathrm{K}$. Thermodynamics of formation. The Journal of Chemical Thermodynamics. 1992;24(9):913-936.

10. Sack RO, Ebel DS. Thermochemistry of Sulfide Mineral Solutions. Reviews in Mineralogy and Geochemistry. 2006;61(1):265-364.

11. Hyde B, O'Keffee M. Marcasite and Pyrite $\left(\mathrm{FeS}_{2}\right)$. Australian Journal of Chemistry. 1996;49(8):867-872. DOI: 10.1071/ CH9960867

12. Bryndzia LT, Scott SD, Spry PG. Sphalerite and hexagonal pyrrhotite geobarometer: experimental calibration and application to the metamorphosed sulfide ores of Broken Hill, Australia. Economic Geology. 1988;83(6):1193-1204.

13. Kloc C, Willeke G, Bucher E. Flux growth and electrical transport measurements of pyrite $\left(\mathrm{FeS}_{2}\right)$. Journal of Crystal Growth. 1993;131(3-4):448-452.

14. Wenk HR, Bulakh A. Minerals: Their Constitution and Origin. Cambridge: Cambridge University Press; 2004. 647 p.

15. Wilke KT, Schultze D, Töfer K. Kristallisation von disulfiden aus schmelzlösungen. Journal of Crystal Growth. 1967;1(1):4144.

16. Srivastava R, Saxena A, Ingole S. n-Type iron pyrite $\left(\mathrm{FeS}_{2}\right)$ thinfilms obtained at different sulfur vapor pressures. Chalcogenide Letters. 2017;14(6):227-237.

17. Nielsen HP, Frandsen FJ, Dam-Johansen K, Baxter LL. The implications of chlorine-associated corrosion on the operation of biomass-fired boilers. Progress in Energy and Combustion Science. 2000;26(3):283-298.

18. Tronina EM, et al. Vestnik Liningradskogo Universiteta. Seriya Phisicheskaya i Chimicheskaya, 1969, No. 10. P 83 (in Russian).

19. Abishev DN, Pashinkin AS. Magnetic Iron Sulfides. Alma-Ata: Nauka; 1981. 131 p. (in Russian)

20. Fleet ME. The crystal structure of a pyrrhotite $\left(\mathrm{Fe}_{2} \mathrm{Ss}\right)$. Acta Crystallographica B. 1971;27:1864-1867.

21. Inman D, Bowling JE, Lovering DG, White SH. Electrochemistry of Molten Salts. In: Hills GJ, ed. Electrochemistry - SpecialistPeriodical Reports. Volume 4. London: The Chemical Society; 1974. p. 78-120.

22. Khalaghi B, Kvalheim E, Tokushige M, Teng L, Seetharaman S, Haarberg GM. Electrochemical Behaviour of Dissolved Iron Chloride in $\mathrm{KCl}+\mathrm{LiCl}+\mathrm{NaCl}$ Melt at $550^{\circ} \mathrm{C}$. ECS Transactions. 2014;64(4):301-310. DOI: 10.1149/06404.0301ecst 
23. Zavrazhnov AY, Turchen DN, Goncharov EG, Zlomanov VP. Manometric method for the study of P-T-X diagrams. Journal of Phase Equilibria. 2001;22(4):482-490. DOI: 10.1361/105497101770333063

24. Lidin RA, Andreyeva LL, Molochko VA. Spravochnik po neorganicheskoy chimii. Moscow: Chimiya; 1987. 320 p. (in Russian)

25. Pashinkin AS, Spivak MM, Malkova AS. Application of Partial Pressure. Diagrams in Metallurgy. Moscow, Metallurgiya; 1984. 160 p. (in Russian)

26. Pilgrim RF, Ingraham TR. Thermodynamics of the Chlorination of iron, Cobalt, Nickel and Copper Sulphides. Canadian Metallurgical Quarterly. 1967;6(1):39-54.
27. Zavrazhnov AY, Zartsyn ID, Naumov AV, Zlomanov VP, Davydov AV. Composition Control of Low-Volatile Solids Through Chemical Vapor Transport Reactions. I. Theory of Selective Chemical Vapor Transport. Journal of Phase Equilibria and Diffusion. 2007;28(6):510-516.

28. Zavrazhnov AY, Naumov AV, Pervov VS, Riazhskikh MV. Chemical vapor transport for the control of composition of low-volatile solids: II. The composition control of indium sulfides: Technique of the charge dilution. Thermochimica Acta. 2012;532:96-102.

29. Zavrazhnov A, Naumov A, Sidey V, Pervov V. Composition control of low-volatile solids through chemical vapor transport reactions. III. The example of gallium monoselenide: Control of the polytypic structure, non-stoichiometry and properties. Thermochimica Acta. 2012;527:118-124. 